\title{
Фазовый переход в монокристалле YАG при фемтосекундной лазерной записи
}

\author{
А.Г. Охримчук ${ }^{1,2}$, А.С. Липатьев ${ }^{1}$, Е.В. Жариков ${ }^{3,4}$, Г. Орлова ${ }^{5}$,

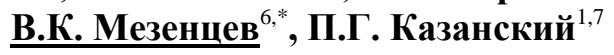 \\ ${ }^{1}$ Международный цеентр лазерных технологий, Российский химико-технологический университет \\ имени Д.И. Менделеева, ул. Героев Панфиловцев, 20, г. Москва 125480 \\ ${ }^{2}$ Научный иентр волоконной оптики РАН, ул.Вавилова, 38, г.Москва 119333 \\ ${ }^{3}$ Российский химико-технологический университет имени Д.И. Менделеева, \\ Миусская площадь, 9, г. Москва 125047 \\ ${ }^{4}$ Институт общей физики им. А.М. Прохорова РАН, ул.Вавилова, 38, г.Москва 119333 \\ ${ }^{5}$ НИИ «Полюс» им. М.Ф. Стельмаха, ул. Введенского, 3, к.1, г. Москва 117342 \\ ${ }^{6}$ Университет Астон, Бирмингем, В4 7ЕТ, Великобритания \\ ${ }^{7}$ Исследовательский иеетр оптоэлектроники, Университет Саутгемптон, \\ Саутгемптон SO17 1BJ, Великобритания \\ *E-mail: v.mezentsev@aston.ac.uk
}

DOI:10.31868/RFL2018.174-175

В докладе описано наблюдение фазового перехода в монокристалле YAG $\left(\mathrm{Y}_{3} \mathrm{Al}_{5} \mathrm{O}_{12}\right)$ в кристаллическую фазу перовскита $\mathrm{YAP}\left(\mathrm{YAlO}_{3}\right)$ в процессе микромодификации монокристалла фемтосекундными (фс) лазерными импульсами. Микромодификация материалов фс лазерными импульсами (фс-запись) в настоящее время является перспективной технологией в современной фотонике после двух декад впечатляющего прогресса [1]. Обычно такую запись используют для формирования таких оптических структур как волноводы, решетки, разветвители и т.п. в аморфных и кристаллических диэлектрических и полупроводниковых материалах с широким спектром применений. Оптические структуры в кристаллах имеют ряд преимуществ, по сравнению со стеклообразными материалами, например значительно более высокую теплопроводность, а также возможности применения в качестве нелинейных или активных материалов. В настоящей работе использовалась стандартная схема фс-записи с фокусировкой фс лазерных импульсов под поверхностью кристалла, который перемещается механической системой для записи дорожек (треков). Результаты записи типичного трека показаны. на Рис. 1,
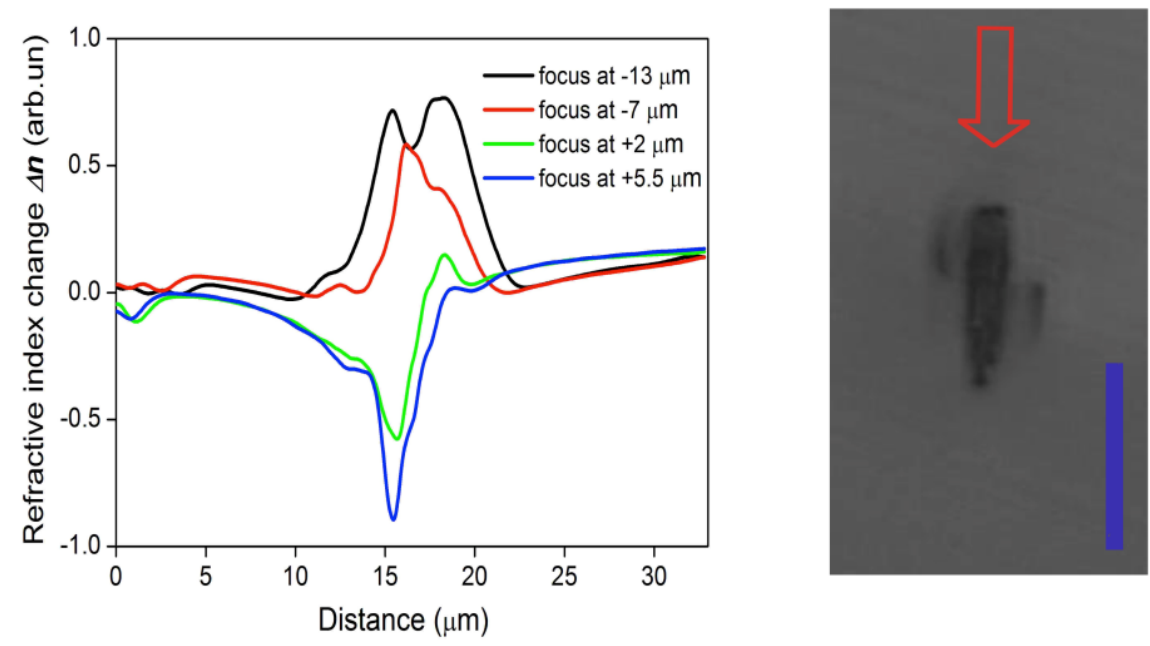

Рис. 1. Слева: примеры профилей показателя преломления в одном из треков, записанных при скорости перемещения образца 3.2 мм/сек. Справа: микрофотография поперечного сечения трека. Красная стрелка показывает направление лазерного пучка при записи, длина синего отрезка соответствует 20 мкм. 
Контроль фс-записи осуществлялся оптимизацией ключевых операционных параметров: мощности импульсов и скорости перемещения кристалла относительно фокуса лазерного пучка. В процессе записи лазерные импульсы локально нагревают фокальную область вплоть до расплавления кристалла. Перегретый расплав существует в течение нескольких микросекунд и затем возвращается в твердую фазу с модифицированной микроструктурой. В настоящей работе особое внимание уделено структуре модифицированного материала.
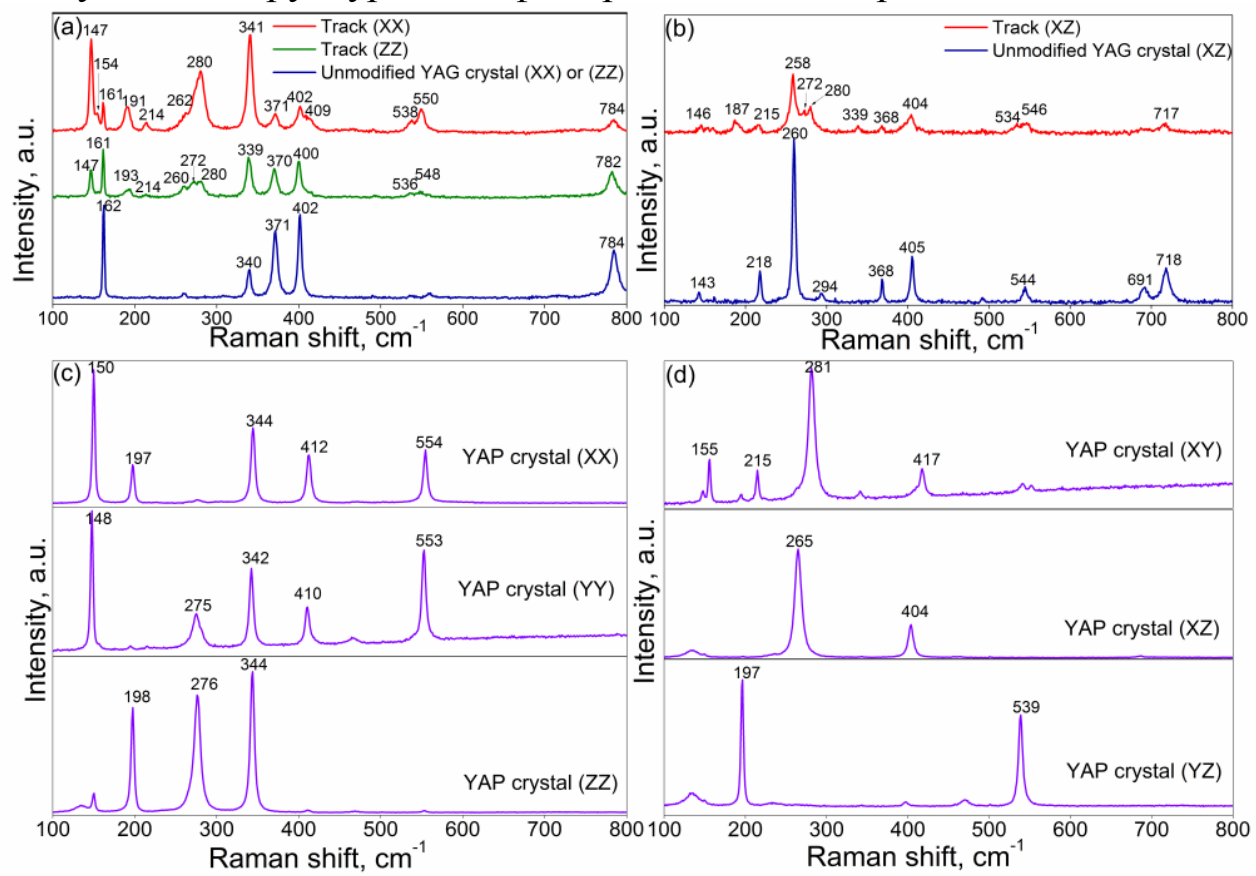

Рис. 2. Поляризованные Рамановские спектры, полученные при облучении центральной области трека (a) и в немодифицированной области кристалла YAG (b) по сравнению со спектрами монокристалла YAP (c,d). Поляризации возбуждающего и рассеянного пучков показаны в скобках: a) и c) для параллельных поляризаций; b) и d) для кросс-поляризаций.

Подобные исследования, практически, отсутствуют в практике фс-записи. Обычно считается, что поглощение энергии фс-импульсов приводит к нарушению кристаллической структуры и, возможно, аморфизации материала в окрестности фокальной области. Мы впервые наблюдали фазовый переход монокристалла YAG в кристаллическую форму перовскита YАР. Это подтверждается результатами Рамановской спектроскопии, приведенными на Рис. 2. Обнаружены дополнительные, по сравнению с монокристаллом YAG, интенсивные линии, характерные для монокристалла ҮАР. Показано, что наиболее интенсивные YАРлинии $\left(147 \mathrm{~cm}^{-1}, 341 \mathrm{~cm}^{-1}\right)$ появляются при скорости перемещения образца более 2 мм/сек и появление новой фазы YАР внутри монокристалла YAG носит пороговый характер. Проведенный нами моделирование распределения температуры при экспериментальных параметрах фс-записи показывает, что такой фазовый переход происходит при достижении пиковой температуры точки плавления и при типичных скоростях перемещения образца время существования перегретого расплава размером в несколько микрон составляет несколько микросекунд. При обратном переходе в твердую фазу возникает монокристаллическая структура YAP.

\section{Литература}

[1] R. Osellame, G. Cerullo, R. Ramponi (Eds.), Femtosecond Laser Micromachining, Springer (2012) 